\title{
Medication Regimens for Managing Stable Asthma
}

\author{
Susanne Meghdadpour FNP PhD and Njira L Lugogo MD \\ Introduction \\ Asthma Phenotypes and Endotypes \\ Review of a Stepwise Approach for Managing Stable Asthma \\ Assessment of Contributing Factors \\ Asthma Follow-up, Assessing Adherence, and Education Are Essential \\ to Asthma Outcomes \\ New Approaches to Managing Stable Asthma \\ Intermittent Dosing of Controllers Therapies in Asthma \\ Alternative Medications for the Management of Asthma \\ Long Acting Muscarinic Antagonists (Long-Acting Anticholinergic): \\ Tiotropium and Umeclidinium \\ Phosphodiesterase-4 Inhibitor: Roflumilast \\ 5-Lipooxygenase Antagonists: Zileuton \\ Macrolide Antibiotic: Azithromycin \\ Special Population Considerations \\ Asthma COPD Overlap \\ African-American Patients and Safety of LABAs \\ Summary Recommendations for Clinicians Providing Care to Patients With \\ Stable Asthma
}

\begin{abstract}
Guideline-based management of asthma was developed as a means of standardizing asthma therapies and of improving outcomes. The National Asthma Education and Prevention Program and the Global Initiative for Asthma guidelines provide recommendations to care providers about the routine management of asthma. There has been rapid development of new therapies for asthma, specifically with the advent of new drug delivery devices and biologic therapies for severe asthma. We are increasingly recognizing that asthma is a heterogenous disease with a diverse underlying pathophysiology, and therefore, it is imperative for care providers to begin to understand asthma phenotypes and endotypes, and the implications of these classifications on management, especially of severe refractory asthma. This article serves as a review of guideline-based therapy for asthma and includes updates on alternative therapies, new approaches that use previously recognized therapies, and special populations with asthma. Key words: asthma; management; phenotypes; guidelines. [Respir Care 2018;63(6):759-772. ( 2018 Daedalus Enterprises]
\end{abstract}

\section{Introduction}

Asthma is a heterogeneous disease that is characterized by both inflammation and airways hyper-responsiveness. Asthma affects millions of adults and children worldwide and is associated with a significant degree of morbidity. Guideline-based management of asthma has been recommended since the 1990s as a means of standardizing asthma treatment across the age spectrum and as a way of summarizing the best available evidence on the management of asthma. The National Asthma Education and Prevention Program ${ }^{1}$ (NAEPP) and the Global Initiative for Asthma ${ }^{2}$ (GINA) guidelines are meant to empower care providers with tools to help manage asthma, with specific recommendations about selecting initial therapies, systematically assessing response, and adjusting therapies based on the individual response to medications. 
The NAEPP guidelines ${ }^{1}$ were last updated in 2007 and included a key change in asthma management priorities. The NAEPP 2007 guidelines $^{1}$ shifted from a focus on severitybased asthma treatment recommendations to one that is focused on achieving optimal asthma control regardless of underlying severity. Asthma severity is an inherent feature of the disease, and there has been increased recognition that severity cannot always be altered; however, asthma control can be optimized regardless of the underlying severity of disease. Per the NAEPP guidelines, ${ }^{1}$ good control for patients $>12$ y old includes the following: asthma symptoms $\leq 2$ days/ $w k$, nighttime awakenings $\leq 2$ times a month, short-acting $\beta_{2}$ agonist (SABA) use $\leq 2$ days/wk, no interference with normal activity, and $\mathrm{FEV}_{1}$ of $\geq 80 \%$ predicted.

The current guidelines ${ }^{1,2}$ recommend systematic approaches to determining the degree of asthma symptoms and then assessing impairments caused by these symptoms with standardized questionnaires such as the Asthma Control Test and the Asthma Control Questionnaire. These instruments can be administered during clinician visits, and adjustments in therapy are made based on the degree to which the individual patient's asthma is controlled or uncontrolled. The GINA guidelines ${ }^{2}$ (2017) included the addition of newer asthma therapies that were not in the previous guidelines, including the use of tiotropium and anti-interleukin-5 targeted therapies. Both guidelines are consistent in the recommendation that corticosteroid-based anti-inflammatory therapies are the baseline treatment for all patients with asthma, with the addition of bronchodilators (both short acting and long acting), leukotriene antagonists, and targeted biologic therapies as adjunctive therapies if asthma control is not achieved..$^{1,2}$ This paper reviews current recommendations and approaches to care per the current guidelines, and suggests that treatment, both now and in the future, should also be driven by consideration of phenotypes and endotypes associated with an individual's

Dr Lugogo is affiliated with Division of Pulmonary and CRITICAL CARE Medicine, Department of Medicine, University of Michigan, Ann Arbor, Michigan. Dr Meghdadpour is affiliated with Division of Pulmonary, Department of Pediatrics, Allergy and Sleep Medicine, Duke University, Durham, North Carolina.

Dr Lugogo discloses relationships with Sanofi, AstraZeneca, GlaxoSmithKline, Merck, and Teva. Dr Meghdadpour has disclosed no conflicts of interest.

Dr Lugogo presented a version of this paper at the 56th RESPIRATORY CARE Journal Conference, Respiratory Medications for COPD and Adult Asthma: Pharmacologic Actions to Clinical Applications, held June 2223, 2017 in St Petersburg, Florida.

Correspondence: Njira L Lugogo MD, 300 North Ingalls St Suite 2C40, Ann Arbor, MI 48109-5400. E-mail: nlugogo@umich.edu.

DOI: $10.4187 /$ respcare. 05957 asthma. These classifications may significantly impact the management of asthma, especially refractory asthma. ${ }^{1,2}$

\section{Asthma Phenotypes and Endotypes}

Asthma is a heterogeneous disease composed of a combination of symptoms, inflammation, and lung function impairments. However, it is being increasingly recognized that a variety of pathophysiologic mechanisms lead to the manifestation of asthma symptoms. Phenotypes are defined as the observable properties of an organism that are produced by the interaction of genotype and the environment. Endotype is proposed to be a subtype of a condition defined by a distinct pathophysiologic mechanism. ${ }^{3}$ For example, eosinophilic asthma is the phenotype but the endotype would be late onset eosinophilic asthma driven by interleukin-5. The primary inflammatory mediator of asthma was previously thought to be underlying allergic and eosinophilic inflammation, and led to the recommendation that inhaled steroids should be the cornerstone of therapy in persistent asthma.

We now understand that a large proportion of patients with asthma (up to $50 \%$ of patients with mild-to-moderate asthma) do not have underlying eosinophilic inflammation, which makes it unlikely that a response to inhaled steroids will occur. ${ }^{4-6}$ This indicates that a significant number of patients would benefit more from initial therapy with bronchodilators, such as long acting muscarinic antagonists monotherapy, or by using alternative anti-inflammatory therapies, such as theophylline, roflumilast, or leukotriene modifiers. Although, the evidence that supports alternative approaches is mounting, it is too early to make changes to the asthma guidelines. The fact that patients may receive therapies that are both expensive and highly unlikely to be beneficial underscores the importance of correctly identifying asthma phenotypes, particularly in severe asthma when targeted therapies can be administered.

The key barrier to correct identification of asthma phenotypes and endotypes in clinical settings is the inability to access a readily available clinical test that accurately categorizes the type of inflammation present in the lungs of patients with asthma. Sputum remains the accepted standard to identify the presence of eosinophils and neutrophils in the lungs of patients with asthma, but, with few exceptions, sputum testing remains a research tool, and many centers do not have the capability to perform sputum differential cell counts in patients with asthma as a means of guiding therapy. Until these challenges can be addressed and further evidence to guide medical decision-making can be accumulated, there is little chance that personalized medicine in asthma management will be fully realized. Alternative approaches to help identify phenotypes and endotypes of asthma are being developed, including the use 

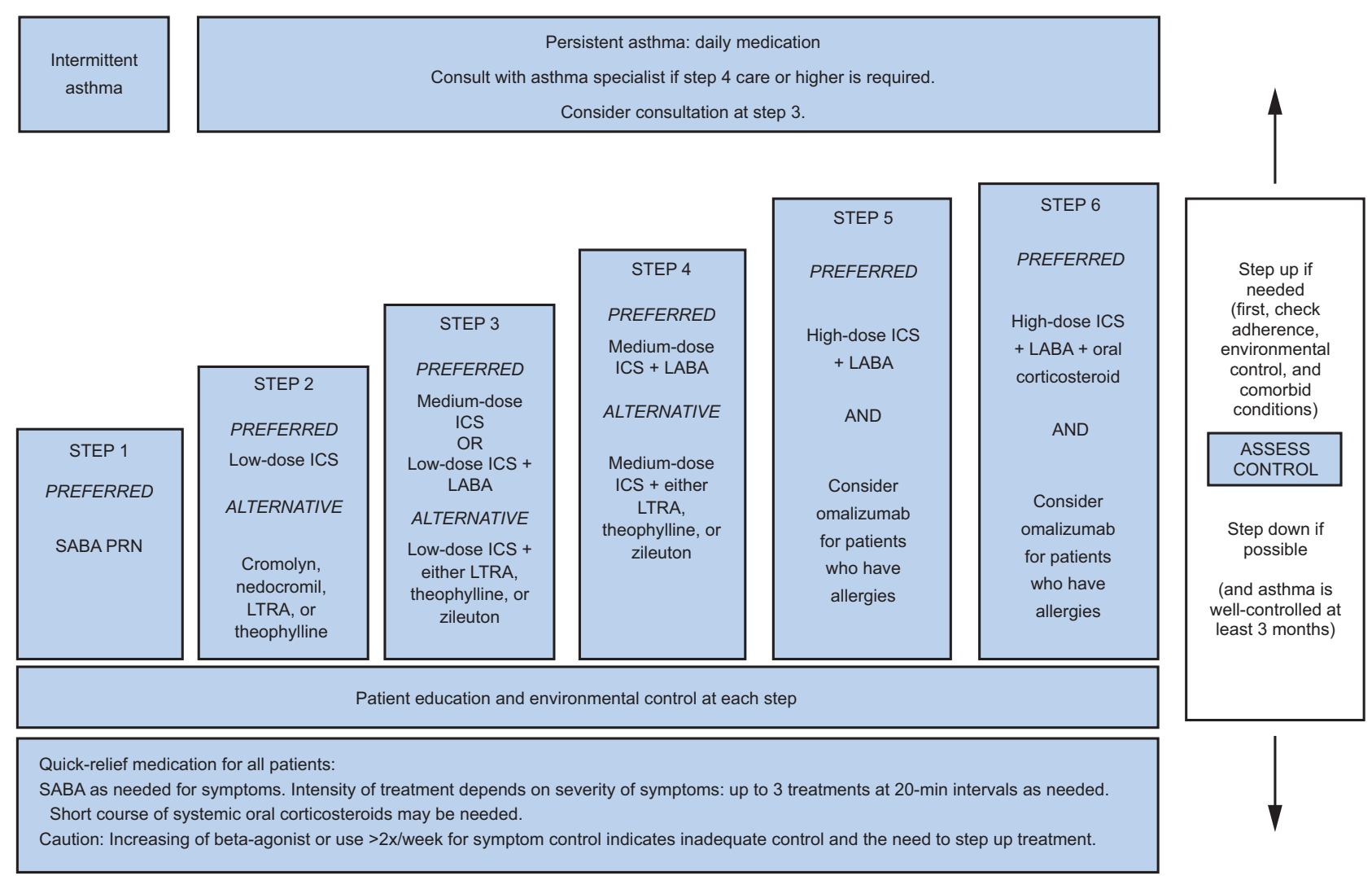

Fig. 1. National Asthma Education and Prevention Program stepwise approach to managing asthma in patients $>12$ y old. ICS $=$ inhaled corticosteroid; LABA = long-acting $\beta$ agonist; SABA = short-acting $\beta$ agonist; LTRA = leukotriene receptor antagonist; PRN = prescribed as needed. From Reference 1, with permission.

of sputum-based proteomics; nasal brushings; transcriptomics; and surrogate measurements of inflammation, such as the fraction of exhaled nitric oxide, blood eosinophils, and serum immunoglobulin E levels. Most of these markers require additional validation before being widely used. The closest we have come to personalized medicine in asthma is in severe asthma in which targeted biologic therapies are administered based on serum immunoglobulin E (omalizumab) and peripheral eosinophils (reslizumab, mepolizumab, and benralizumab). Phenotyping is critical in the management of severe asthma, and clinicians should strongly consider incorporating this into routine practice at this time..$^{7,8}$

\section{Review of a Stepwise Approach for Managing Stable Asthma}

Both the NAEPP and GINA guidelines ${ }^{1,2}$ rely on a stepwise approach to managing asthma symptoms. The NAEPP guidelines ${ }^{1}$ include 6 steps based on asthma severity, which is defined on the basis of lung function impairments, exacerbations, and medication utilization (Fig. 1). Step 1 asthma is mild and intermittent, and typically requires "as needed" bronchodilator therapy; step 2 asthma is encompassed by more persistent symptoms but contin- ues to be associated with normal lung function. ${ }^{1}$ The persistent symptoms require the addition of daily therapies aimed at decreasing these symptoms, which include low doses of inhaled steroids or theophylline or leukotriene antagonists. ${ }^{1}$ As the steps increase, the patient's asthma is characterized by more persistent symptoms and abnormalities in lung function, with an increased likelihood of having exacerbations, nighttime symptoms, daily symptoms, and use of bronchodilator therapies for rescue (steps 3,4). ${ }^{1}$

As asthma worsens, inhaled steroid doses are increased and the addition of maintenance bronchodilator therapies is encouraged. In the NAEPP guidelines, ${ }^{1}$ the bronchodilator that is recommended is long-acting $\beta$ agonist (LABA), although there is a significant amount of evidence available to support the use of tiotropium as an alternative to LABA or as adjunctive therapy. The data on tiotropium will be discussed further in long acting muscarinic antagonists (long acting anticholinergic) section of this paper. Steps 5 and 6 asthma are severe persistent and often refractory to inhaled steroids and bronchodilators in isolation. ${ }^{1}$ These patients have the most significant burden of disease in asthma and also have the highest risk of poor outcomes. In these patients, whose asthma is not con- 


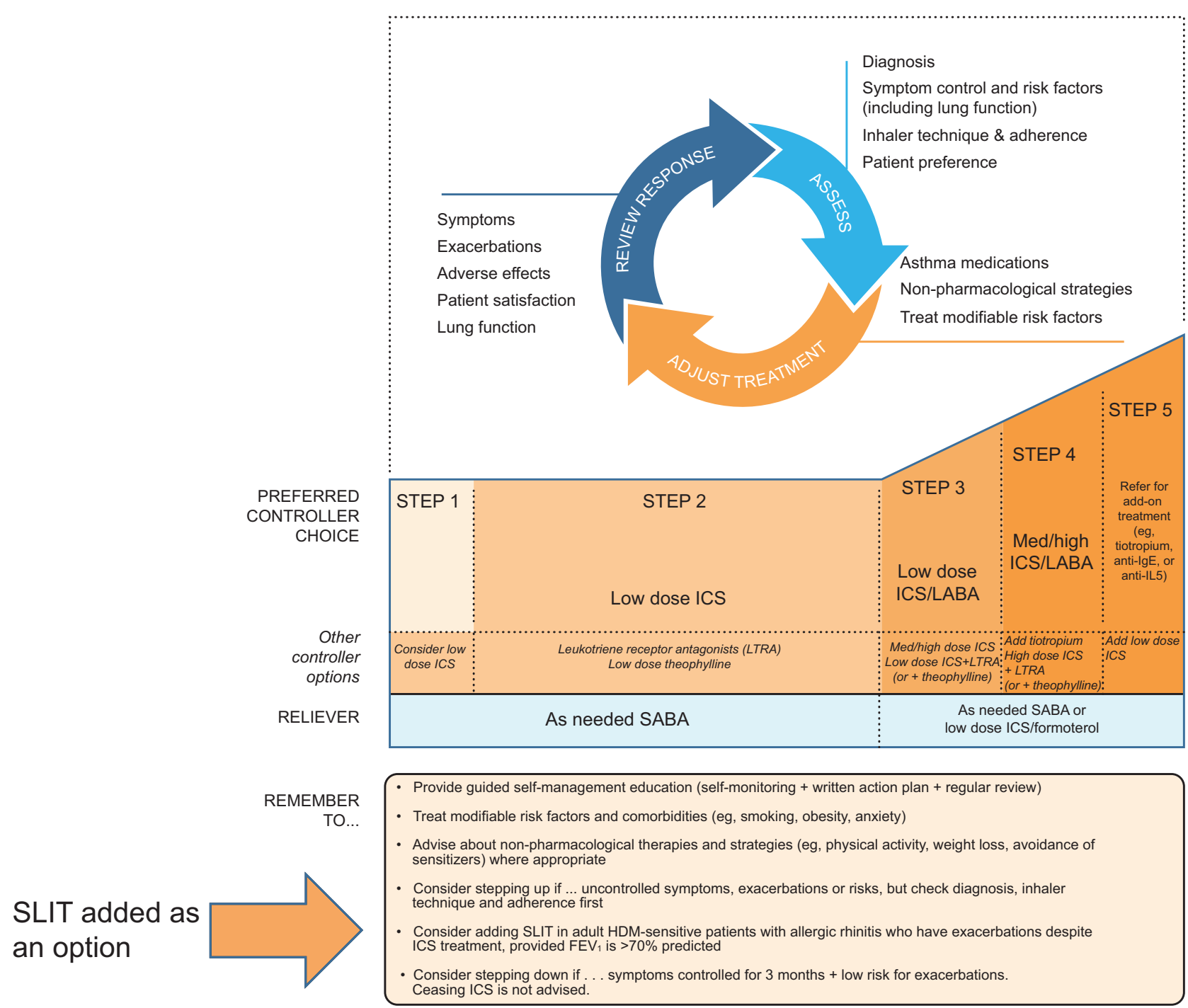

Fig. 2. Global Initiative for Asthma stepwise approach to control asthma symptoms and reduce risk. ICS = inhaled corticosteroid; LABA = long-acting $\beta$ agonist; OCS = oral corticosteroid; SLIT = sublingual immunotherapy; HDM = house dust mite. From Reference 2, with permission.

trolled on high-dose inhaled steroids and LABA, there are several alternatives, including the use of tiotropium, biologic therapies that target interleukin-5 and immunoglobulin E, and bronchial thermoplasty.

The GINA guidelines ${ }^{2}$ use a similar stepwise approach to asthma management, and there are 5 steps included in the recommendations (Fig. 2). Step 1 patients require intermittent therapy with consideration for the addition of daily maintenance therapy if there are persistent symptoms that remain uncontrolled; in step 2 therapy, the addition of maintenance inhaled steroids is important in achieving asthma control. ${ }^{2}$ Steps 3 and 4 require the addition of maintenance bronchodilators, with increasing doses of inhaled steroids, and step 5 encompasses severe asthma, and these patients may require oral corticosteroids and biologic therapies, in addition to their inhaled combination therapies. ${ }^{2}$ Unlike the NAEPP guidelines, ${ }^{1}$ the GINA guidelines ${ }^{2}$ include the use of tiotropium in steps 4 and 5 asthma as a means of achieving asthma control. In addition, use of inhaled steroids and/or LABA therapy for rescue is included. The GINA guidelines ${ }^{2}$ recommend a continuum that is encompassed by assessing patients, adjusting therapies, reviewing response, and reassessing patients to determine if further adjustments are required. In addition, adherence, medication tolerance, management of comorbid conditions, and contributing factors are recommended. Interestingly, the latest GINA guidelines ${ }^{2}$ include the use of sublingual immunotherapy for a target population of patients with allergic rhinitis, exacerbations, $\mathrm{FEV}_{1}>70 \%$ predicted and house dust mite allergen sensitivity (Fig. 2). 


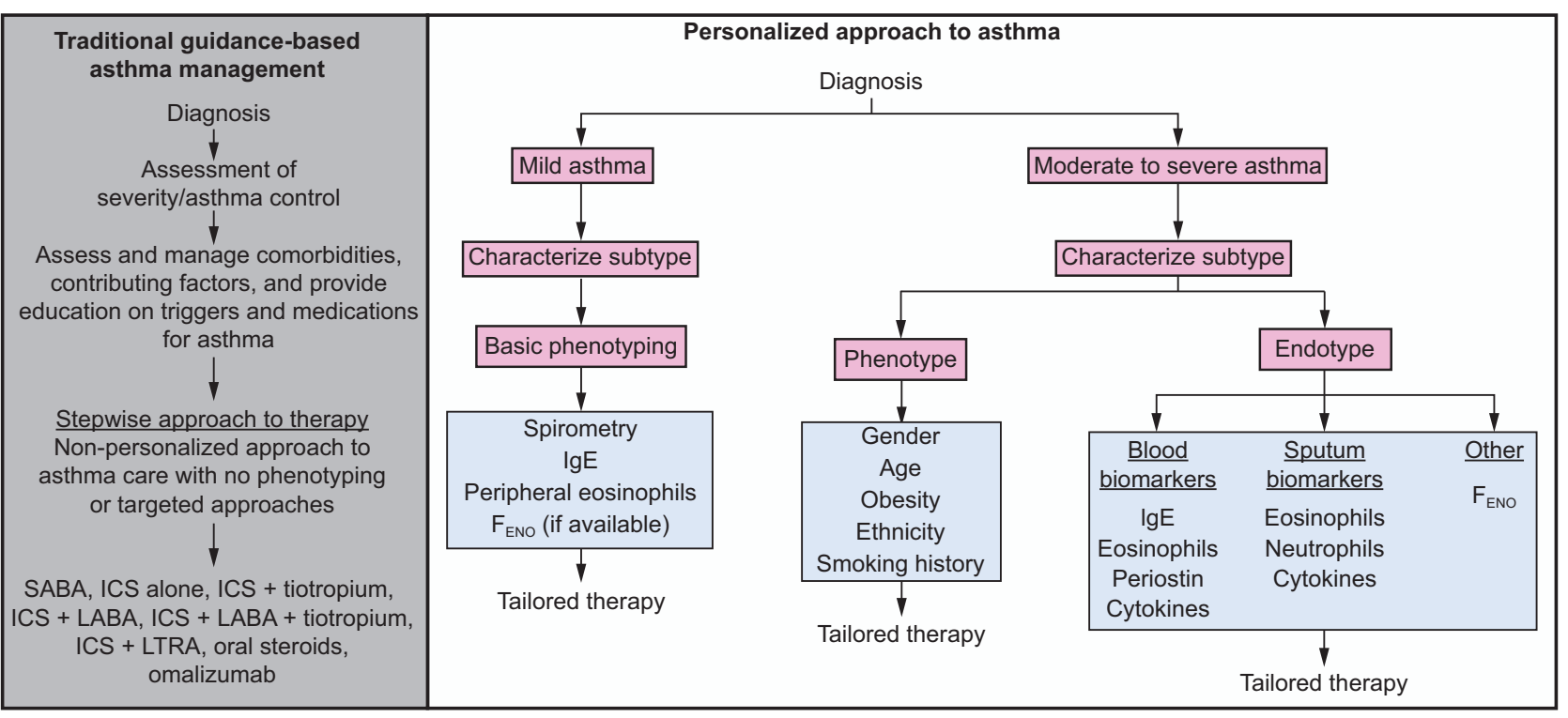

Fig. 3. Proposed personalized approach to asthma therapy. SABA $=$ short-acting $\beta$ agonist; ICS $=$ inhaled corticosteroid; LABA $=$ long-acting $\beta$ agonist; LTRA = leukotriene receptor antagonist.

\section{Assessment of Contributing Factors}

A well-rounded approach to mitigating contributing factors must be included in the management of patients with asthma if optimal control is to be achieved. It is imperative to assess comorbidities, such as gastroesophageal reflux disease, allergic rhinitis and atopy, sinus disease, sleep apnea, vocal cord dysfunction, and obesity, throughout all the steps of asthma management. In addition, management of environmental exposures and/or triggers, tobacco use, and irritants is essential.

\section{Asthma Follow-up, Assessing Adherence, and Education Are Essential to Asthma Outcomes}

The guidelines recommend assessing patients by obtaining baseline lung function measurements and establishing the level of asthma control, managing contributing factors and comorbid conditions, and then making adjustments to therapy if indicated. ${ }^{1,2}$ Patients should then be followed up at 3-month intervals to determine if asthma control has been achieved and if there are opportunities to either further optimize therapy or to step-down treatment. The ultimate goal is to determine the right amount of medication required to achieve control without exposing patients to the risks associated with the use of unnecessarily high doses or excessive numbers of medication.

An additional key issue that must be addressed is asthma education and the improvement of health literacy in patients with asthma. Practitioners must ensure that patients are adherent to asthma therapies, and it is imperative not only to identify non-adherence but to address the issues that are causing non-adherence to improve adherence and thus asthma outcomes. The complex issues of adherence are addressed in an article Titled: Patient Adherence Issues in this edition of the journal.

As the landscape of inhaled therapies and comfort level regarding devices used to deliver medications becomes more complex, the gaps in knowledge of patients, providers, and care teams is an added concern. There currently are multiple devices on the market, including the Respimat (Boehringer Ingelheim, Germany), dry powder inhaler, pressurized metered-dose inhaler, Diskus and Ellipta devices, each with a unique actuation, priming, and administration approach. Improper technique when using these devices is a common issue and leads to poor drug delivery and to predictably poor treatment response rates. Advances must be made in teaching patients how to correctly use the devices prescribed to them to improve asthma outcomes. It is often challenging for a busy practitioner to address inhaler teaching, but this must be a key component of any asthma management program.

\section{New Approaches to Managing Stable Asthma}

\section{Intermittent Dosing of Controller Therapies in Asthma}

The guidelines recommend regular rather than intermittent use of long-term controllers (inhaled steroids and longacting bronchodilators) in patients with persistent asthma. ${ }^{1,2}$ However, there has been growing interest in intermittent dosing of controller medications. In a recent study, the intermittent use of short-acting albuterol combined with 
inhaled steroids was associated with similar rates of asthma exacerbations as regular use of beclomethasone or combination therapy (albuterol-beclomethasone) in subjects with mild persistent asthma. ${ }^{9}$ Furthermore, in this study, regular use of inhaled steroid therapy had no additive benefits over intermittent "as needed" use with regard to the reduction of asthma exacerbations, which required oral steroids in adults and children with persistent asthma. ${ }^{10}$ Regular use of inhaled steroids resulted in improvements in asthma control and symptom-free days. However, it did not confer additional benefits with regard to $\mathrm{FEV}_{1}$, quality of life, airway hyper-reactivity, adverse events, hospitalizations, and emergency department visits for asthma. ${ }^{10}$ Based on the available data, clinicians can consider the use of intermittent inhaled steroid or combination therapies in carefully selected patients with mild persistent asthma.

\section{Alternative Medications for the Management of Asthma}

The use of bronchodilator-based and inhaled corticosteroid (ICS) based therapies for asthma are reviewed in other articles Bronchodilators and Inhaled and Systemic Corticosteroids in this issue of the Journal. There are several other new promising therapies, including anticholinergic and alternative anti-inflammatory medications that are not currently widely used to treat asthma.

\section{Long Acting Muscarinic Antagonists (Long-Acting Anticholinergic): Tiotropium and Umeclidinium}

Tiotropium is an anticholinergic drug that targets the muscarinic receptors and results in bronchodilatory effects in the lungs of patients with asthma and COPD. Tiotropium has been shown to improve $\mathrm{FEV}_{1}$ in addition to ICS or as an additive therapy to inhaled steroids and LABA combination therapy ${ }^{11,12}$ (see Table 1 for multiple other studies). In addition, tiotropium increases the time to first exacerbation and decreases severe exacerbations when added on to combination therapy in severe asthma. ${ }^{13}$ In African-American subjects, tiotropium was non-inferior to LABAs and did not demonstrate any differences in safety measures and adverse events. ${ }^{14}$ The initial studies used the HandiHaler (Boehringer Ingelheim, Germany) device, and more recent trials included the Respimat device, which was shown to be efficacious in improving $\mathrm{FEV}_{1}$ in children, adolescents, and adults with asthma. ${ }^{15-17}$ The FDA cleared the use of the Spiriva Respimat (Boehringer Ingelheim, Germany) for treatment of adult and pediatric patients with asthma. The use of tiotropium as monotherapy in asthma is an ongoing area of investigation. Tiotropium has been included in the GINA guidelines ${ }^{2}$ as an alternate add-on treatment option for steps 4 and 5 in adult patients with a history of exacerbations and will undoubtedly be considered for addition to future revisions of the NAEPP guidelines. ${ }^{1}$

Umeclidinium, a newer addition to this class of drugs, has been studied as both monotherapy and add-on therapy to inhaled steroids in asthma. There was a modest improvement in trough $\mathrm{FEV}_{1}$ in subjects who were steroid naive and treated with umeclidinium monotherapy ${ }^{18}$ and umeclidinium resulted in improvements in $\mathrm{FEV}_{1}$ in addition to inhaled steroids when compared with inhaled steroids alone, an effect that was reportedly more prominent in those subjects with fixed obstruction. ${ }^{19}$ Studies to determine the role of umeclidinium and glycopyrrolate in asthma are ongoing, and it is still unclear about how these medications will be incorporated in the future. Umeclidinium is currently not FDA-cleared for asthma.

\section{Phosphodiesterase-4 Inhibitor: Roflumilast}

Roflumilast is a phosphodiesterase-4 inhibitor that has both bronchodilatory and anti-inflammatory effects, and is currently cleared by the FDA for the treatment of adult patients with COPD associated with chronic bronchitis and a history of frequent exacerbations. Roflumilast has been studied in asthma as monotherapy as well as add-on therapy to inhaled steroids (Table 2 for multiple studies). There are studies that demonstrated non-inferiority when compared with inhaled steroids with improvements in $\mathrm{FEV}_{1}$ in patients with mild-to-moderate persistent asthma. In addition, roflumilast results in increased time to first exacerbations and has some effects on improvement in asthma quality of life and symptoms. The drug is associated with nausea and gastrointestinal adverse effects that are transient and improve with time. In addition, roflumilast results in weight loss in some patients. The potential weight loss and possibility of associated improvements in asthma control in those who are obese may be a desirable effect of roflumilast therapy in this subpopulation of patients with asthma. ${ }^{20}$ However, in a large clinical trial in asthma, roflumilast did not result in significant changes in weight. ${ }^{21}$ Although roflumilast is a promising therapy for asthma, phase 3 studies have not been completed and the drug is currently not cleared by the FDA for treatment of asthma. The main limitation has been the vexing adverse effects of therapy that must be balanced with the potential benefits and weighed against better tolerated alternatives.

\section{5-Lipooxygenase Antagonists: Zileuton}

Montelukast (Singulair, Merck, Kenilworth, NJ) is a more commonly used leukotriene receptor antagonist cleared by the FDA for treatment of asthma in patients ages $\geq 12$ months and is considered step 2 therapy in the NAEPP guidelines ${ }^{1}$ with anti-inflammatory properties. The less-familiar drug, zileuton is a 5-lipoxygenase inhibitor 


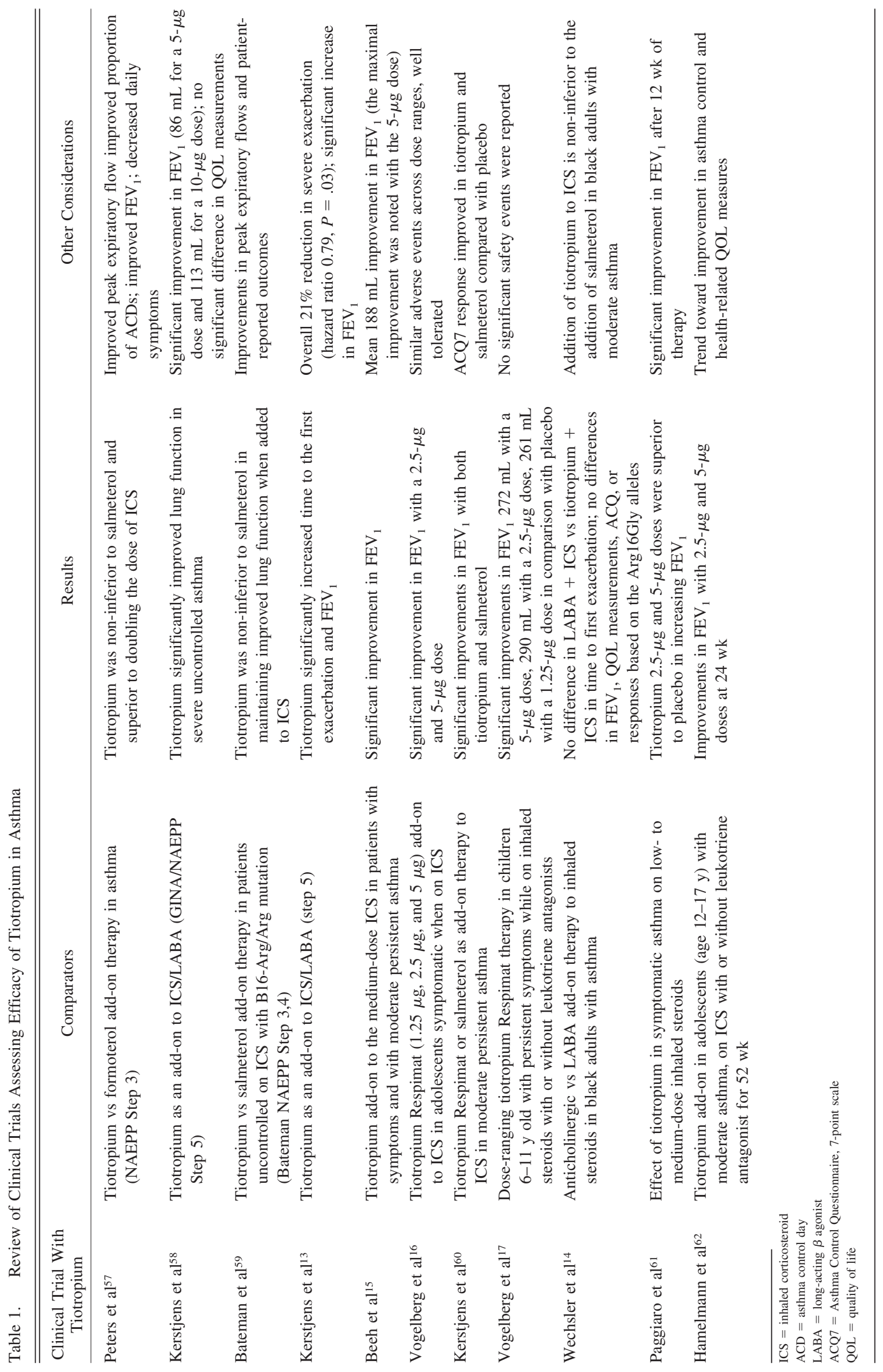




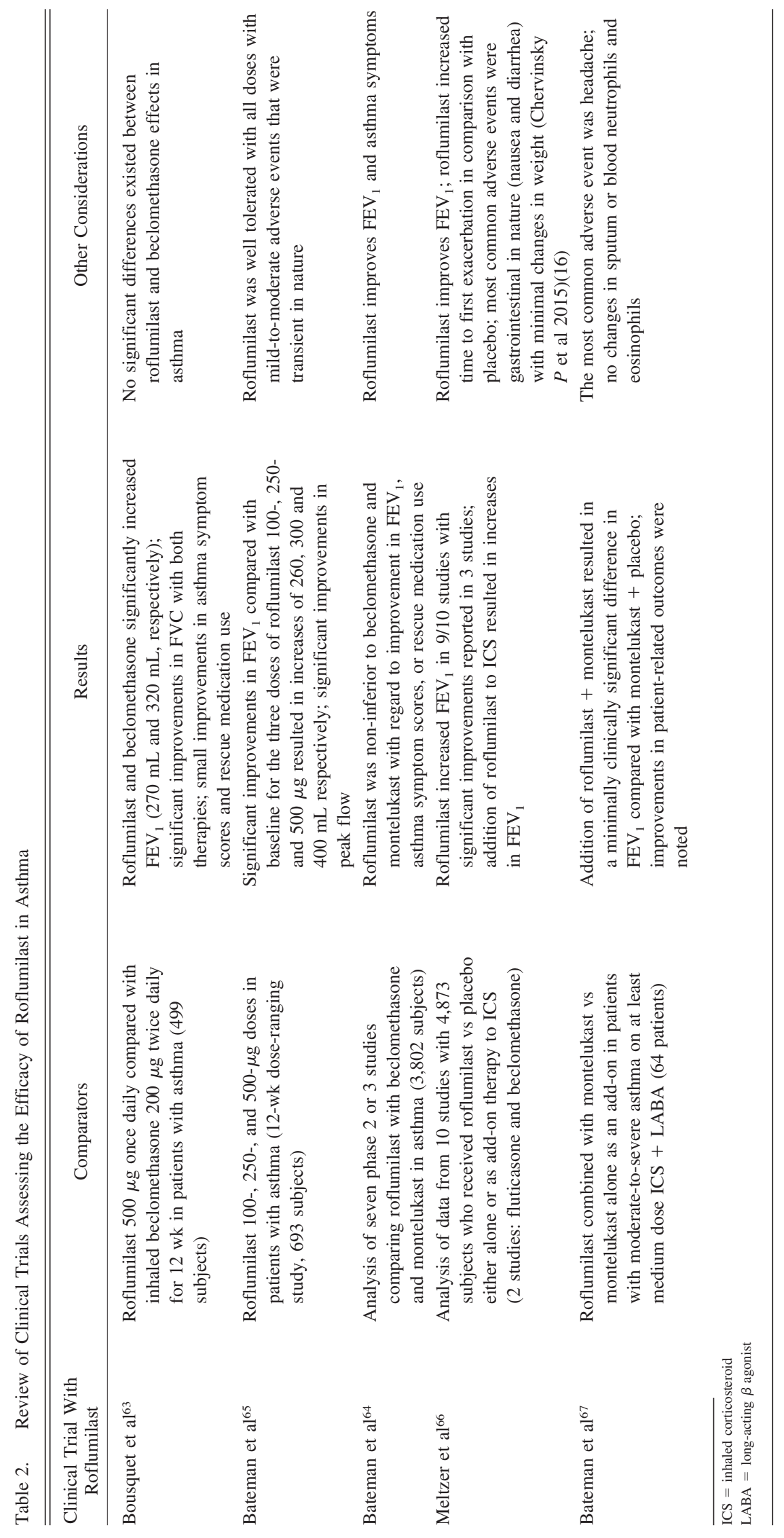


that significantly decreases the production of leukotrienes. It has effects on both lung function and inflammation, which result in significant improvements in $\mathrm{FEV}_{1}$, asthma quality of life, and exacerbations (see Table 3 for multiple studies). Furthermore, zileuton decreases inflammation in the lungs of patients with asthma. The drug has been cleared by the FDA for the treatment of asthma in persons $\geq 12 \mathrm{y}$ and is included in the NAEPP guidelines ${ }^{1}$ for treatment of patients with step 3 or higher asthma. Zileuton is associated with a small risk of causing elevated liver function test results; this is more likely to occur within the first 3 months of treatment. Elevations in liver function test results are transient and resolve with discontinuation of therapy; therefore, it is recommended that liver function be monitored on a regular basis after the initiation of zileuton therapy..$^{22}$ In spite of the addition of zileuton into the guidelines, its widespread use has been hampered by concerns over liver-related adverse effects and short half-life that require frequent dosing. ${ }^{23}$ In addition, poor insurance coverage for the medication coupled with its high costs resulted in decreased utilization.

\section{Macrolide Antibiotic: Azithromycin}

Azithromycin is an azalide antibiotic, closely related to macrolides, that possesses antimicrobial and immunomodulatory effects, and there has been growing interest in using it as a therapy in severe persistent asthma. There have been mixed results from clinical trials that assessed the use of macrolides as adjunctive therapy in asthma with a recent study that demonstrated no effects in asthma overall but a subgroup analysis indicated that perhaps macrolides may still have effects on exacerbation reduction in patients with severe non-eosinophilic asthma. ${ }^{24,25}$ There are conflicting results with regard to the effect of azithromycin on asthma exacerbations. Although azithromycin reportedly decreased the number of exacerbations and improved quality of life in one study, ${ }^{26}$ therapy did not decrease the duration of acute symptoms or the time to resolution of acute asthma symptoms. In addition, in a separate exacerbation study (AZALEA), azithromycin did not result in improvement in asthma control, quality of life, or lung function. ${ }^{27}$ There is uncertainty about the long-term role of macrolides in asthma, unlike in COPD in which these therapies demonstrated efficacy in reducing exacerbations in select patients with COPD with frequent exacerbations. ${ }^{28} \mathrm{~A}$ recent metaanalysis demonstrated an increased risk of hearing loss and antimicrobial resistance in subjects with chronic lung disease treated with long-term macrolides, and, therefore, these issues need to be taken into consideration as the role of macrolides in asthma is defined in the future. ${ }^{29}$

\section{Special Population Considerations}

\section{Asthma COPD Overlap}

Asthma and COPD were previously thought to be 2 distinct diseases without any significant overlap. However, recently, a new phenomenon was described, and the term asthma COPD overlap was coined to encompass a disease in which these disorders may co-exist, with features of both being present. ${ }^{30}$ Asthma COPD overlap accounts for approximately $15-25 \%$ of obstructive airway diseases and is associated with worse outcomes than either asthma or COPD alone. ${ }^{31-35}$ Patients with asthma COPD overlap have an increased risk of exacerbations; pharmacologic implications exist when determining the appropriate therapies for these patients. ${ }^{36}$

The exact definition of asthma COPD overlap continues to be a topic of ongoing discussion, ${ }^{37-40}$ and the origin of the disease may be asthma with the subsequent development of chronic obstruction or COPD with allergic features. ${ }^{41,42}$ Patients with asthma and with a lack of reversible air flow obstruction and with a significant tobacco use history are excluded from asthma clinical trials, which thus limits the generalizability of therapies cleared by the FDA for the treatment of asthma to this unique group of patients. This holds true for patients with COPD with any history of asthma or allergic disease and reversibility. In 2014, the GINA guidelines ${ }^{2}$ first addressed the issue of asthma COPD overlap, stressing the importance of assessing risk factors for exacerbations, including nonpharmacologic therapies and strategies in this subgroup of patients. 43

Therapeutic approaches in patients with asthma COPD overlap require an increased ability to accurately define the potential underlying mechanisms of inflammation (endotypes) that can allow for targeted therapies. ${ }^{44}$ Biomarkers are desperately needed to help characterize these phenotypes and to deal with the inherent inflammatory heterogeneity that is present in asthma COPD overlap. ${ }^{45}$ For instance, some patients with COPD predominantly have eosinophilic inflammation and, as such, should be treated with inhaled steroids rather than with bronchodilators alone, contrary to the current recommended guidelines for the treatment of COPD (the Global Initiative for Chronic Obstructive Lung Disease). ${ }^{46,47}$

Tobacco cessation and vaccinations are cornerstones of therapy in asthma COPD overlap, and the use of ICS and bronchodilators is important. Further research is required to determine the role of biologic medications in asthma COPD overlap. ${ }^{48}$ The impact of asthma COPD overlap on asthma and COPD outcomes will continue to be an area of active investigation, and clinical trials are needed to help define the most appropriate interventions for these patients who bear a more significant burden of disease. 


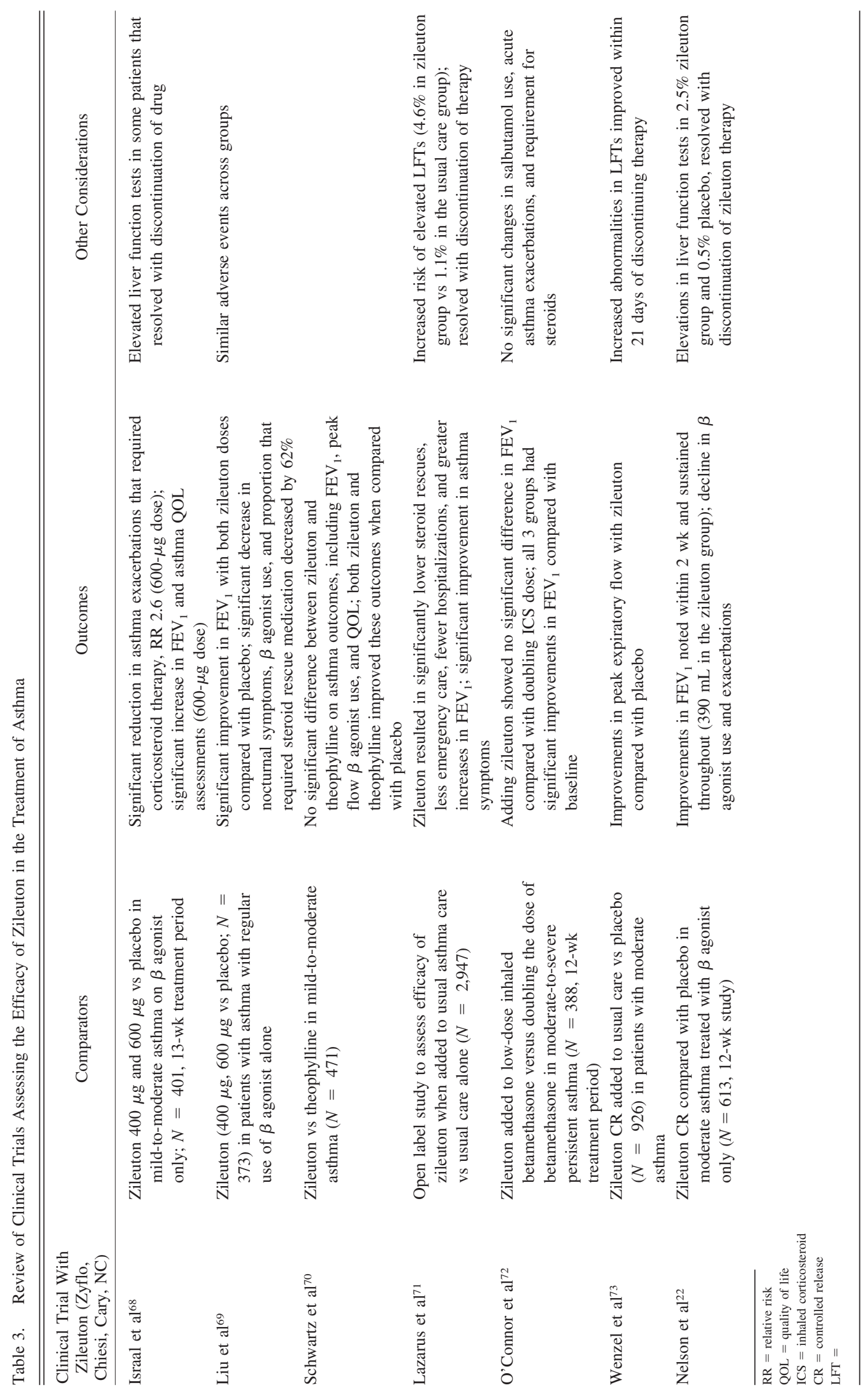




\section{African-American Patients and Safety of LABAs}

LABAs are a mainstay of asthma therapy for patients with persistent asthma who remain uncontrolled on inhaled steroid monotherapy. In 2006, the SMART trial was published and raised concern about a potential for increased adverse events in patients of African descent who had asthma. ${ }^{43,49}$ The SMART trial included 26,355 subjects who received salmeterol or placebo for the management of asthma. ${ }^{49}$ In interim analyses, the study was terminated secondary to a small but statistically significant increase in overall mortality with regular use of salmeterol. Furthermore, there were increased respiratory-related events and asthma-related deaths with salmeterol that seemed to occur predominantly in African-American subjects, who represented $18 \%$ of the study population. ${ }^{49}$

Meta-analysis confirmed the significant benefits of LABA therapy in asthma; however, safety concerns remained. ${ }^{50}$ In 2007, the FDA issued a black box warning on any drug formulations that contains LABAs that mandated against using these medications as monotherapy without concomitant inhaled steroids. ${ }^{51}$ In addition, safety studies were mandated to determine if, in fact, there were residual safety concerns when LABA used in combination with inhaled steroids was prescribed to African-American patients. ${ }^{52}$

Since the SMART trial, ${ }^{49}$ multiple large clinical trials have been completed that demonstrated efficacy of LABAs in combination with ICS in decreasing exacerbations ${ }^{53}$ and asthma control in African-Americans with an acceptable safety profile and no indication of increased mortality. ${ }^{14,54,55}$ Based on these studies, the FDA recently removed the black box warnings on LABAs. ${ }^{56}$ What is yet undetermined is whether increased doses of inhaled steroids will be superior to adding on LABAs in AfricanAmericans, and this is an area of ongoing investigation.

\section{Summary Recommendations for Clinicians Providing Care to Patients With Stable Asthma}

Clinicians who care for patients with asthma need to be increasingly aware of the implications of phenotypes and endotypes on disease activity and response to therapy. Increased recognition of the underlying pathophysiology that drives a patient's symptoms and level of control can help guide decision-making regarding asthma therapies in a more tailored way (Fig. 3). Comorbid conditions and contributing factors should be taken into consideration and mitigated. A structured approach to the management of patients with asthma in the clinical setting should be developed, including the use of standardized questionnaires to routinely assess the 2 important domains: risk (exacerbations) and control. This approach allows clinicians to determine if adjustments to therapy are warranted. Fur- thermore, it is essential to discern whether patients have been non-adherent with their asthma therapies and to identify and target reasons for non-adherence. Asthma education is an essential part of care delivery, particularly given the inhaler confusion that exists and is worsening with the ever-expanding number of devices that are on the market. Ultimately, the goal is to decrease exacerbations, optimize lung function, and decrease symptoms that negatively impact each patient's quality of life.

\section{REFERENCES}

1. National Heart, Lung, and Blood Institute, National Asthma Education and Prevention Program. Expert Panel Report 3: guidelines for the diagnosis and management of asthma, 2007. http://www.nhlbi. nih.gov/guidelines/asthma/asthgdln.pdf. Accessed April 18, 2018.

2. Global Initiative for Asthma (GINA). GINA Report, Global Strategy for Asthma Management and Prevention. www.ginasthma.org. Accessed April 18, 2018.

3. Lötvall J, Akdis CA, Bacharier LB, Bjermer L, Casale TB, Custovic A, et al. Asthma endotypes: a new approach to classification of disease entities within the asthma syndrome. J Allergy Clin Immunol 2011;127(2):355-360.

4. McGrath KW, Icitovic N, Boushey HA, Lazarus SC, Sutherland ER, Chinchilli VM, et al; Asthma Clinical Research Network of the National Heart, Lung, and Blood Institute. A large subgroup of mildto-moderate asthma is persistently noneosinophilic. Am J Respir Crit Care Med 2012;185(6):612-619.

5. Szefler SJ, Martin RJ, King TS, Boushey HA, Cherniack RM, Chinchilli VM, et al; Asthma Clinical Research Network of the National Heart Lung, and Blood Institute. Significant variability in response to inhaled corticosteroids for persistent asthma. J Allergy Clin Immunol 2002;109(3):410-418.

6. Douwes J, Gibson P, Pekkanen J, Pearce N. Non-eosinophilic asthma: importance and possible mechanisms. Thorax 2002;57(7): 643-648.

7. Dunn RM, Wechsler ME. Anti-interleukin therapy in asthma. Clin Pharmacol Ther 2015;97(1):55-65.

8. Darveaux J, Busse WW. Biologics in asthma-the next step toward personalized treatment. J Allergy Clin Immunol Pract 2015;3(2): 152-160; quiz 161.

9. Papi A, Canonica GW, Maestrelli P, Paggiaro P, Olivieri D, Pozzi E, et al; BEST Study Group. Rescue use of beclomethasone and albuterol in a single inhaler for mild asthma. N Engl J Med 2007;356(20): 2040-2052.

10. Chauhan BF, Chartrand C, Ducharme FM. Intermittent versus daily inhaled corticosteroids for persistent asthma in children and adults. Cochrane Database Syst Rev 2013;(2):CD009611.

11. Price D, Fromer L, Kaplan A, van der Molen T, Roman-Rodriguez M. Is there a rationale and role for long-acting anticholinergic bronchodilators in asthma? NPJ Prim Care Respir Med 2014; 24:14023.

12. Busse WW, Dahl R, Jenkins C, Cruz AA. Long-acting muscarinic antagonists: a potential add-on therapy in the treatment of asthma? Eur Respir Rev 2016;25(139):54-64.

13. Kerstjens HA, Engel M, Dahl R, Paggiaro P, Beck E, Vandewalker $\mathrm{M}$, et al. Tiotropium in asthma poorly controlled with standard combination therapy. N Engl J Med 2012;367(13):1198-1207.

14. Wechsler ME, Yawn BP, Fuhlbrigge AL, Pace WD, Pencina MJ, Doros G, et al; BELT Investigators. Anticholinergic vs Long-Acting beta-Agonist in Combination With Inhaled Corticosteroids in Black Adults With Asthma: The BELT Randomized Clinical Trial. JAMA 2015;314(16):1720-1730. 


\section{Medications for Stable Asthma}

15. Beeh KM, Moroni-Zentgraf $\mathrm{P}$, Ablinger $\mathrm{O}$, Hollaenderova Z, Unseld A, Engel M, et al. Tiotropium Respimat(R) in asthma: a doubleblind, randomised, dose-ranging study in adult patients with moderate asthma. Respir Res 2014;15:61.

16. Vogelberg C, Engel M, Moroni-Zentgraf P, Leonaviciute-Klimantaviciene M, Sigmund R, Downie J, et al. Tiotropium in asthmatic adolescents symptomatic despite inhaled corticosteroids: a randomised dose-ranging study. Respir Med 2014;108(9):12681276

17. Vogelberg C, Moroni-Zentgraf $\mathrm{P}$, Leonaviciute-Klimantaviciene M, Sigmund R, Hamelmann E, Engel M, Szefler S. A randomised dose-ranging study of tiotropium Respimat in children with symptomatic asthma despite inhaled corticosteroids. Respir Res 2015; $16: 20$.

18. Lee LA, Briggs A, Edwards LD, Yang S, Pascoe S. A randomized, three-period crossover study of umeclidinium as monotherapy in adult patients with asthma. Respir Med 2015;109(1):63-73.

19. Lee LA, Yang S, Kerwin E, Trivedi R, Edwards LD, Pascoe S. The effect of fluticasone furoate/umeclidinium in adult patients with asthma: a randomized, dose-ranging study. Respir Med 2015; 109(1):54-62

20. Juel CT, Ali Z, Nilas L, Ulrik CS. Asthma and obesity: does weight loss improve asthma control? a systematic review. J Asthma Allergy 2012;5:21-26.

21. Chervinsky P, Meltzer EO, Busse W, Ohta K, Bardin P, Bredenbroker D, Bateman ED. Roflumilast for asthma: Safety findings from a pooled analysis of ten clinical studies. Pulm Pharmacol Ther 2015; 35(Suppl):S28-S34.

22. Nelson H, Kemp J, Berger W, Corren J, Casale T, Dube L, et al. Efficacy of zileuton controlled-release tablets administered twice daily in the treatment of moderate persistent asthma: a 3-month randomized controlled study. Ann Allergy Asthma Immunol 2007; 99(2):178-184.

23. Dahlén SE. Treatment of asthma with antileukotrienes: first line or last resort therapy? Eur J Pharmacol 2006;533(1-3):40-56.

24. Brusselle GG, Vanderstichele C, Jordens P, Deman R, Slabbynck H, Ringoet $\mathrm{V}$, et al. Azithromycin for prevention of exacerbations in severe asthma (AZISAST): a multicentre randomised double-blind placebo-controlled trial. Thorax 2013;68(4):322-329.

25. Wong EH, Porter JD, Edwards MR, Johnston SL. The role of macrolides in asthma: current evidence and future directions. Lancet Respir Med 2014;2(8):657-670.

26. Gibson PG, Yang IA, Upham JW, Reynolds PN, Hodge S, James AL, et al. Effect of azithromycin on asthma exacerbations and quality of life in adults with persistent uncontrolled asthma (AMAZES): a randomised, double-blind, placebo-controlled trial. Lancet 2017; 390(10095):659-668

27. Johnston SL, Szigeti M, Cross M, Brightling C, Chaudhuri R, Harrison T, et al; AZALEA Trial Team. Azithromycin for Acute Exacerbations of Asthma : The AZALEA Randomized Clinical Trial. JAMA Intern Med 2016;176(11):1630-1637.

28. Albert RK, Connett J, Bailey WC, Casaburi R, Cooper JA Jr, Criner GJ, et al; COPD Clinical Research Network. Azithromycin for prevention of exacerbations of COPD. N Engl J Med 2011;365(8):689698.

29. Li H, Liu DH, Chen LL, Zhao Q, Yu YZ, Ding JJ, et al. Metaanalysis of the adverse effects of long-term azithromycin use in patients with chronic lung diseases. Antimicrob Agents Chemother 2014;58(1):511-517.

30. Gibson PG, Simpson JL. The overlap syndrome of asthma and COPD: what are its features and how important is it? Thorax 2009;64(8): 728-735.

31. Papaiwannou A, Zarogoulidis P, Porpodis K, Spyratos D, Kioumis I, Pitsiou G, et al. Asthma-chronic obstructive pulmonary disease over- lap syndrome (ACOS): current literature review. J Thorac Dis 2014;(6 Suppl 1):S146-S151.

32. Barrecheguren M, Esquinas C, Miravitlles M. The asthma-chronic obstructive pulmonary disease overlap syndrome (ACOS): opportunities and challenges. Curr Opin Pulm Med 2015;21(1):74-79.

33. Nielsen M, Bårnes CB, Ulrik CS. Clinical characteristics of the asthma-COPD overlap syndrome-a systematic review. Int J Chron Obstruct Pulmon Dis 2015;10:1443-1454.

34. Alshabanat A, Zafari Z, Albanyan O, Dairi M, FitzGerald JM. Asthma and COPD Overlap Syndrome (ACOS): A Systematic Review and Meta Analysis. PLoS One 2015;10(9):e0136065.

35. Gelb AF, Christenson SA, Nadel JA. Understanding the pathophysiology of the asthma-chronic obstructive pulmonary disease overlap syndrome. Curr Opin Pulm Med 2016;22(2):100-105.

36. Louie S, Zeki AA, Schivo M, Chan AL, Yoneda KY, Avdalovic M, et al. The asthma-chronic obstructive pulmonary disease overlap syndrome: pharmacotherapeutic considerations. Expert Rev Clin Pharmacol 2013;6(2):197-219

37. Braman SS. The chronic obstructive pulmonary disease-asthma overlap syndrome. Allergy Asthma Proc 2015;36(1):11-18.

38. Gibson PG, McDonald VM. Asthma-COPD overlap 2015: now we are six. Thorax 2015;70(7):683-691.

39. Slats A, Taube C. Asthma and chronic obstructive pulmonary disease overlap: asthmatic chronic obstructive pulmonary disease or chronic obstructive asthma? Ther Adv Respir Dis 2016;10(1):57-71.

40. Putcha N, Wise RA. Asthma-Chronic Obstructive Pulmonary Disease Overlap Syndrome: Nothing New Under the Sun. Immunol Allergy Clin North Am 2016;36(3):515-528.

41. Bateman ED, Reddel HK, van Zyl-Smit RN, Agusti A. The asthmaCOPD overlap syndrome: towards a revised taxonomy of chronic airways diseases? Lancet Respir Med 2015;3(9):719-728.

42. Postma DS, Rabe KF. The Asthma-COPD Overlap Syndrome. N Engl J Med 2015;373(13):1241-1249.

43. Boulet LP, FitzGerald JM, Reddel HK. The revised 2014 GINA strategy report: opportunities for change. Curr Opin Pulm Med 2015; 21(1):1-7.

44. Tho NV, Park HY, Nakano Y. Asthma-COPD overlap syndrome (ACOS): A diagnostic challenge. Respirology 2016;21(3):410-418.

45. Hizawa N. Clinical approaches towards asthma and chronic obstructive pulmonary disease based on the heterogeneity of disease pathogenesis. Clin Exp Allergy 2016;46(5):678-687.

46. Barnes PJ. Therapeutic approaches to asthma-chronic obstructive pulmonary disease overlap syndromes. J Allergy Clin Immunol 2015; 136(3):531-545.

47. GOLD guidelines, 2017. http://goldcopd.org/gold-2017-globalstrategy-diagnosis-management-prevention-copd/

48. Hines KL, Peebles RS Jr. Management of the Asthma-COPD Overlap Syndrome (ACOS): A Review of the Evidence. Curr Allergy Asthma Rep 2017;17(3):15.

49. Nelson HS, Weiss ST, Bleecker ER, Yancey SW, Dorinsky PM; SMART Study Group. The Salmeterol Multicenter Asthma Research Trial: a comparison of usual pharmacotherapy for asthma or usual pharmacotherapy plus salmeterol. Chest 2006;129(1):15-26.

50. Walters EH, Gibson PG, Lasserson TJ, Walters JA. Long-acting beta2-agonists for chronic asthma in adults and children where background therapy contains varied or no inhaled corticosteroid. Cochrane Database Syst Rev 2007;(1):CD001385.

51. Cazzola M, Matera MG. Safety of long-acting beta2-agonists in the treatment of asthma. Ther Adv Respir Dis 2007;1(1):35-46.

52. Currie GP, Lee DK, Lipworth BJ. Long-acting beta2-agonists in asthma: not so SMART? Drug Saf 2006;29(8):647-656.

53. Wells KE, Peterson EL, Ahmedani BK, Severson RK, GleasonComstock J, Williams LK. The relationship between combination inhaled corticosteroid and long-acting beta-agonist use and severe 


\section{Medications for Stable Asthma}

asthma exacerbations in a diverse population. J Allergy Clin Immunol 2012;129(5):1274-1279.e2.

54. Bailey W, Castro M, Matz J, White M, Dransfield M, Yancey S, Ortega H. Asthma exacerbations in African Americans treated for 1 year with combination fluticasone propionate and salmeterol or fluticasone propionate alone. Curr Med Res Opin 2008;24(6):16691682.

55. Brown RW, O'Brien CD, Martin UJ, Uryniak T, Lampl KL. Longterm safety and asthma control measures with a budesonide/formoterol pressurized metered-dose inhaler in African American asthmatic patients: a randomized controlled trial. J Allergy Clin Immunol 2012; 130(2):362-367.e9.

56. FDA safety letter. 2017. https://www.fda.gov/Safety/MedWatch/ Safety Information/Safety AlertsforHumanMedicalProducts/ ucm590001.htm

57. Peters SP, Kunselman SJ, Icitovic N, Moore WC, Pascual R, Ameredes BT, et al. Tiotropium bromide step-up therapy for adults with uncontrolled asthma. N Engl J Med 2010;363(18):1715-1726.

58. Kerstjens HA, Disse B, Schroder-Babo W, Bantje TA, Gahlemann $\mathrm{M}$, Sigmund R, et al. Tiotropium improves lung function in patients with severe uncontrolled asthma: a randomized controlled trial. J Allergy Clin Immunol 2011;128(2):308-314.

59. Bateman ED, Kornmann O, Schmidt P, Pivovarova A, Engel M, Fabbri LM. Tiotropium is noninferior to salmeterol in maintaining improved lung function in B16-Arg/Arg patients with asthma. J Allergy Clin Immunol 2011;128(2):315-322.

60. Kerstjens HA, Casale TB, Bleecker ER, Meltzer EO, Pizzichini E, Schmidt $\mathrm{O}$, et al. Tiotropium or salmeterol as add-on therapy to inhaled corticosteroids for patients with moderate symptomatic asthma: two repilicate, double-blind, placebo-controlled, parallel-group, active-comparator, randomised trials. Lancet Respir Med 2015;3(5): 367-376.

61. Paggiaro P, Halpin DM, Buhl R, Engel M, Zubek VB, Blahova Z, et al. The effect of tiotropium in symptomatic asthma despite low-tomedium-dose inhaled corticosteroids: a randomized controlled trial. J Allergy Clin Immunol Pract 2016;4(1):104-113

62. Hamelmann E, Bateman ED, Vogelberg C, Szefler SJ, Vandewalker $\mathrm{M}$, Moroni-Zentgraf $\mathrm{P}$, et al. Tiotropium add-on therapy in adolescents with moderate asthma: a 1-year randomized controlled trial. J Allergy Clin Immunol 2016;138(2):441-450.

63. Bousquet J, Aubier M, Sastre J, Izquierdo JL, Adler LM, Hofbauer $\mathrm{P}$, et al. Comparison of roflumilast, an oral anti-inflammatory, with beclomethasone dipropionate in the treatment of persistent asthma. Allergy 2006;61(1):72-78.

64. Bateman ED, Bousquet J, Aubier M, Bredenbroker D, O'Byrne PM. Roflumilast for asthma: Efficacy findings in non-placebo-controlled comparator and dosing studies. Pulm Pharmacol Ther 2015;35 Suppl: S11-S19.

65. Bateman ED, Izquierdo JL, Harnest U, Hofbauer P, Magyar P, Schmid-Wirlitsch C, et al. Efficacy and safety of roflumilast in the treatment of asthma. Ann Allergy Asthma Immunol 2006;96(5):679686.

66. Meltzer EO, Chervinsky P, Busse W, Ohta K, Bardin P, Bredenbroker D, et al. Roflumilast for asthma: Efficacy findings in placebocontrolled studies. Pulm Pharmacol Ther 2015;35 Suppl:S20-S27.

67. Bateman ED, Goehring UM, Richard F, Watz H. Roflumilast combined with montelukast versus montelukast alone as add-on treatment in patients with moderate-to-severe asthma. J Allergy Clin Immunol 2016;138(1):142-149.

68. Israel E, Cohn J, Dube L, Drazen JM. Effect of treatment with zileuton, a 5-lipoxygenase inhibitor, in patients with asthma. A randomized controlled trial. Zileuton Clinical Trial Group. Jama 1996; 275(12):931-936.

69. Liu MC, Dube LM, Lancaster J. Acute and chronic effects of a 5-lipoxygenase inhibitor in asthma: a 6-month randomized multicenter trial. Zileuton Study Group. J Allergy Clin Immunol 1996; 98(5 Pt 1):859-871.

70. Schwartz HJ, Petty T, Dube LM, Swanson LJ, Lancaster JF. A randomized controlled trial comparing zileuton with theophylline in moderate asthma. The Zileuton Study Group. Arch Intern Med 1998; 158(2):141-148.

71. Lazarus SC, Lee T, Kemp JP, Wenzel S, Dube LM, Ochs RF, et al. Safety and clinical efficacy of zileuton in patients with chronic asthma. Am J Manag Care 1998;4(6):841-848.

72. O'Connor BJ, Lofdahl CG, Balter M, Szczeklik A, Boulet LP, Cairns $\mathrm{CB}$. Zileuton added to low-dose inhaled beclomethasone for the treatment of moderate to severe persistent asthma. Respir Med 2007; 101(6):1088-1096.

73. Wenzel S, Busse W, Calhoun W, Panettieri R, Jr., Peters-Golden M, Dube L, et al. The safety and efficacy of zileuton controlled-release tablets as adjunctive therapy to usual care in the treatment of moderate persistent asthma: a 6-month randomized controlled study. J Asthma 2007;44(4):305-310.

\section{Discussion}

Williams: Very nice summary. I don't think the final answer will be coming out in terms of what the next NIH Expert Panel Report version looks like, but I think there is a good summary of the evidence coming from the Agency for Healthcare Research and Quality. Some of the things we can expect, such as the issue of the use of inhaled steroids alone versus inhaled steroids plus as needed steroids when necessary reportedly showed no benefit. They feel comfortable and, thus, they recommend inhaled steroids alone versus intermittent steroids for those $\geq 12$ y old but not for 5-11 y olds because of incomplete evidence. I'm not quite sure I understand what the concern is about triple therapy versus combination therapy, you feel like an inhaled steroid with a LABA is still going to be available to the patient. Is that correct?

\section{Lugogo: Yes.}

Williams: Maybe that there's just going to be some confusion about it?

Lugogo: For example, there are patients who do very well with tiotropium, and they like the delivery with the Respimat device but are not doing as well when they combine tiotropium with a fixed combination ICS/LABA. In some instances, all the formulations on the market have been tried. Some patients do well combining inhaled steroids and LABA plus long acting muscarinic antagonists (eg, one of my patients did best with beclomethasone combined with Tiotropium plus olodaterol [Stiolto, Boehringer Ingelheim, Germany]). I recognize that this is off-label use, so I'm not recommending this approach; however, the more inhalers we have on the market, the higher the number of possible combinations. There may be some bene- 
fits to using combination bronchodilator therapy. For example, if you are on LABA plus long-acting anti-muscarinic antagonists, then you can really ramp up the ICS dosage during exacerbations. Therefore, if the patient takes beclomethasone propionate all the time, then he or she could quadruple the dose during acute asthma episodes. Of course, the FDA is currently still mandating that, if you use a LABA, it needs to be in a fixed combination inhaler. The other thing we find is that patients are completely overwhelmed by the different types of devices; for instance, one patient may have a rescue pMDI, a Respimat inhaler with tiotropium, and inhaled steroids or fixed combination medication in an Ellipta device. This introduces a significant amount of inhaler confusion. The large number of delivery devices is also a big burden on providers who are managing these patients. Especially for primary care physicians; I don't know how a provider would find the time to really educate a patient on the use of 3 different devices during an already time-constrained visit.

MacIntyre: Njira, I don't treat asthma. But say you have a relatively mild patient with asthma who only has intermittent symptoms, what drives you to just give the patient albuterol when necessary versus something simple, like montelukast, versus the ICS/SABA combination? What drives those choices in your mind?

Lugogo: I would recommend prescribing SABA only to patients with exercise-induced asthma or with very mild intermittent asthma, with rare use of SABA, once a month or something. If you have any kind of atopy or allergic rhinitis and exercise-induced symptoms not fully controlled on
SABA, then I would add on a leukotriene inhibitor as first-line therapy. But if you have a little bit more in the way of symptoms, for example, you have seasonal symptoms, or when you get upper respiratory infections, you cough for 3-4 weeks at a time, or you're very aware that, for a month and half in the spring, you'll have issues, then you would qualify for intermittent treatment with ICS. The 2 ways I approach this group of patients is as follows: One subgroup of patients receives intermittent asthma therapy that is administered seasonally. So I'll say, "you' re always sick in April, start your ICS in March, take it for 2 months and then you can stop it for the next 9 months, and if you get sick with any upper respiratory infection, go on your inhaled therapy." The other subgroup is of those without seasonal variation but who really fall off a cliff when they get sick and it takes them forever to recover in spite or oral corticosteroids and other interventions. In those patients, I'll prescribe intermittent SABA/ICS dosing that is initiated the moment they get sick with an upper respiratory infection. This is meant to reduce the morbidity and protracted course.

Mann: I think there's a fair number of patients with fairly severe asthma who really only have problems when they get a cold. My son was a perfect example. He would be fine and stable, but, with a cold, he would be blue and in the emergency department. I eventually started putting him on prednisone when he had a cold. So, I managed my son in a possibly unorthodox way by giving him prednisone during colds and nothing in between. I'm not sure even treatment guidelines would concur with such an approach, but my son's clinicians frankly agreed with my approach. He eventually outgrew his asthma and did fine. I think that supports my second and more significant comment, which is I think its important to understand the difference between treatment guidelines and the FDA and drug labels. The FDA functions under regulatory standards that require a very strong level of evidence for efficacy; we call it substantial. A substantial level of evidence usually means 2 randomized double-blind trials that replicate efficacy. You also have to have a very full and thorough understanding of safety to clear a drug, and FDA cleared indication and label that goes on new medications. Clinical treatment guidelines are different. They can perform a literature review and their experience and attempt to inform clinicians on the practice of medicine. They can go, if you will, beyond the label. I am glad the practice of medicine allows for clinicians to be understanding of various ways to use drugs more broadly. I think the FDA says as well that it's absolutely fine with us, the practice of medicine is important and we don't regulate that. I wouldn't want to go to a clinician who says, "I only prescribe FDA-cleared therapy." That would make me very nervous because there are a lot of gaps and holes. I just want to clarify, when folks criticize the FDA and say: How come you haven't cleared this or that? Everyone is doing it! How come we don't have as-needed use based on this study? Why don't you clear the use of this drug for this population when it's helpful? Such data often fall more appropriately into clinical guidelines or the practice of medicine and only if the data meet regulatory standards and are submitted to the FDA can they be implemented in labeling. 